\title{
THE USE OF EDUCATIONAL TECHNOLOGIES IN THE DEVELOPMENT OF PRESCHOOL CHILDREN
}

\section{Gauhar Djanpeisova}

Associate Professor, Candidate Of Pedagogical Sciences, Head Of The Department Of Methods Of Preschool Education,

Tashkent State Pedagogical University Named After Nizami,, Uzbekistan

Aziza Igamberdieva

Researcher Tashkent State Pedagogical University Named After Nizami,, Uzbekistan

\section{ABSTRACT}

The scientific article presents some didactic approaches to the formation of mathematical concepts in preschool children based on TIPS technologies. The methods and technologies of teaching children mathematics using developmental and logical games and exercises are revealed, the necessity of systematic preparation of children for mastering the school curriculum of mathematics is substantiated.

KEYWORDS: - Teaching and development of children; TIPS technologies mathematical representations, innovative technologies; logical thinking; spatial orientation; game approaches.

\section{INTRODUCTION}

Modern educators have great opportunities to construct author programs on mathematical development of a child, which, however, is impossible without a thorough knowledge of the fundamentals and techniques of mathematic theory that is asked by current programs for pre - school educational establishments and primary schools and referring to successful experienced traditional, alternative and various approaches to the mathematical training of children.

Relevant for the enrichment of existing and creation of new techniques and technologies in child's mathematical development modern requirements represent a direction associated with adapting to the specificity of childhood theory of inventive problem solving (TIPS), heuristic training, and mathematical modeling.

\section{THE MAIN RESULTS AND FINDINGS}

There are three basic approaches to solving problems of any kind:

- Trial and error;

- Activation of sorting options;

- Strong decisions without solid busting options (TIPS).

Scientists F. Bacon, R. Descartes, A. Osborne, F. Zwicky, J. Gordon and others, synthesizing 
CURRENT RESEARCH JOURNAL OF PEDAGOGICS 2(8): 44-51, August

2021 DOI: https://doi.org/10.37547/pedagogics-crjp-02-08-11

ISSN 2767-3278

(C)2021 Master Journals

\section{Crossref do) 81 Google}

Accepted $26^{\text {th }}$ August, 2021 \& Published 31 th August, 2021

philosophical and mathematic approaches have tried to improve the trial and error type. So there appeared methods as brainstorm (A. Osborne), sinekgiki (J. Gordon), multidimensional arrays (F. Zwicky), etc.

Theory of Inventive Problem Solving (TIPS) regularly appeared in the second half of XX century as means to resolve this contradiction. Analysis of tens of thousands of patents of invention allowed to the former of TIPS, G.S. Altshuller make after - blowing conclusion that technical systems evolve by objectively existing laws that are known, identified and offered conscious performing of old and new systems. Invented by the scientist and his followers the system of laws of development of technical systems formed the basis of TIPS ${ }^{1}$.

Areas of application of modern TIPS is very broad: to build plots of literary works, paintings, art (Y.S. Murashkovsky, S.V. Kozlovsky, etc.), biology (V.A. Buhvalov, I.I.Samal, V.I. Timokhov, etc.), mathematics and mathematical development methodology (A.A. Strauning, A.V. Khutorskoy, V.M. Tsurikov and others), geography (T. V. Ivanov and others), pedagogy and psychology (A.N. Tubelsky, N. N. Khomenko, I.S. Yakimanskaya, etc.) - now in Ukrainian laboratories of pedagogy based on TIPS is developed a structure of "Ahead of pedagogy" ( L.I. Shragin, M.I. Meerovitch, etc), even in business (V.G. Siberyakov, S.V .Sychev, V.I. Timokhov, S.A. Fayer, etc.) and advertisement (I. L. Vikent'ev, etc.).

\section{The basic principles upon which TIPS solve} this problem as follows:

- Objectivity of laws: a system developed for the objective laws which must be studied and used in

${ }^{1}$ Kumon Publishing. Subtraction. Grade $1 P D F$. Math Workbook, Kumon Publishing,USA, 2008, 96 pages. the process of solving problems;

- Presence of contradictions: the problem is difficult because it contains a contradiction, which should identify and resolve;

- Concrete solutions: specific resource acquires specific characteristics in specific circumstances.

As a result of the development TIPS became the basis for a practical methodology for analyzing the problems encountered in the functioning of artificial systems. Currently, based on TIPS theory is formed many artificial systems development theory.

\section{Prospects of development of TIPS in the sphere of education are as follows:}

- Visual and remote seminars for teachers and distributing the literature;

- Develop programs and teaching methods of individual behavior and coordination them together;

- Creation of cross - cutting programs of continuous learning in preschool organizations and school.

There is a trend of the escalating TIPS theory to the artificial systems development theory, creative personality, other private spheres, for example, methods of mathematical development.

We define the basic concepts of TIPS, used in children's mathematical development.

Algorithm of inventive problem solving is step by step performing of mental operations, based on objective laws of development of technical systems and suggested to analyze technical problems and find the most effective solutions.

An algorithm for solving problem situations is modification of an algorithm of inventive problem solving, based on objective laws of artificial systems development and designed to analyze problems and find their most effective solutions. 
CURRENT RESEARCH JOURNAL OF PEDAGOGICS 2(8): 44-51, August

2021 DOI: https://doi.org/10.37547/pedagogics-crjp-02-08-11

ISSN 2767-3278

(C)2021 Master Journals

\section{Crossref do) 81 Google}

Accepted $26^{\text {th }}$ August, 2021 \& Published 31 th August, 2021

The system is a set of elements that form when combining the new property, which does not have a single element is designed to perform a specific function.

The ideal system is the structure of the system tends to zero, but the ability to perform its functions at the same time does not decrease (in other words, the system does not exist, but its function retains and works).

Super system is the union, in which the system itself, considered to be a constituent part.

Subsystem is a part of the system.

Element of the system is a trivial part of the system (the trivial degree is conditional, and is corrected within the meaning of the concept of subsystem).

System Operator-3-,9-or 18-screen diagram of powerful thinking. Let us explain: every subject, the object or phenomenon of environment or of the world can be considered as a system, which is a super - system, being one of its parts; interacting with other parts, the system is composed of the cooperating parts - the subsystems (Figure 1).

The product - is the item that you need to change, to move, to produce, measure, etc. Something for which the system is created.

The tool - is the object that interacts directly with the product in order to obtain the desired result.

Resources - are everything, which can be used to solve the problem: substance; field; information; attributes, their values and the associated results (phenomena and effects).

The result - is the result of the application of TIPS to solve the concrete problem, expressed in accessible form: positive result - is the desired objective for the educator, negative is undesirable.
Ideal Final Result (IFR) - obtaining all positive results without any adverse. There are different levels of ideal final result, for which the negative result:

- disappears at the lowest cost;

- eliminates itself;

- disappears, eliminating even one or more negative results;

- transforms into a positive result, etc.

Contradiction - is a discrepancy of two signs to the same subject. A typical formulation of the elementary contradiction is this: for a set of attribute values function attribute - argument has a value of $A$, but for a different set of values of the attribute - argument attribute - value function has not $\mathrm{A}$. In other words, this property is the relationship between the two parameters of the system, in which a change in one of them in the right direction is an unacceptable change in the other.

Fantogramm - is a table containing a list of typical for different sets of universal and specific indicators and methods of their main changes. It is used for the development of imagination, based on non - trivial logic.

The following TIPS principles of minimizing contradictions that you can use with preschool children in the course of logical - mathematical development at the planning level of educational situations, and with the direct solution of problems.

1. Fragmentation:

a) Divide the object into independent parts;

b) Perform object collapsible;

c) Increase the degree of crushing object.

2. Introduction: separated from the object "interfering" part ("interfering" property) or, alternatively, select only the desired part or the desired property. 
CURRENT RESEARCH JOURNAL OF PEDAGOGICS 2(8): 44-51, August

2021 DOI: https://doi.org/10.37547/pedagogics-crjp-02-08-11

ISSN 2767-3278

(C)2021 Master Journals

Crossref doi) 81 Google

Accepted $26^{\text {th }}$ August, 2021 \& Published 31 th August, 2021

3. The principle of local quality:

a) Move from a homogeneous structure of the object or the environment (external action) to the non - uniform;

b) Different parts of an object must perform a variety of functions;

c) Each part of the object must be in terms of most favorable for its operation.

4. Asymmetry:

a) Move from the symmetrical shape of the object to the asymmetrical;

b) If the object is already asymmetrical, increase the degree of asymmetry.

5. Merge:

a) Combine homogeneous objects or for related operations objects;

b) Combine in homogeneous or time related operations.

6. Versatility: An object performs several different functions, eliminating the need for other sites.

7. The principle of "Matryoshka":

a) One object is arranged inside the other, which in its turn is inside a third, etc;

b) One object passes through another cavity.

8. Preliminary anti action; if the terms of the problem need to make some action, it is necessary to make anti action in advance.

9. Preliminary action:

a) Perform in advance the desired action (fully or partially);

b) Pre - arrange the objects so that they could come into effect without spending much time to deliver the most convenient place.

10. The principle of "advance padded cushion": to compensate for the relatively low reliability of an object previously prepared emergency funds.

11. The principle of "reverse":

a) Instead of an action dictated by the terms of the tasks to carry out the opposite effect;

b) Make a moving part of an object or an environment stable and fixed - moving;

c) Rotate the object "upside down", to turn it.

12. Spheroid: go on from straight parts to curve ones, from flat surfaces to spherical, from parts made in the form of a cube or parallelepiped to the ball constructions.

\section{Dynamic:}

a) The characteristics of the volume (or the environment) should be changed so as to be optimal at each stage of the work;

b) Divide the object into parts that can move relatively to each other;

c) If the object is stationary in general, to make it mobile, moving.

14. The principle of "Blessing in disguise":

a) Using harmful factors (especially harmful action of environment) to obtain a positive effect;

b) To eliminate the harmful factor by adding it to other harmful factors;

c) Enhance the harmful factor to such a degree that it considered not to be harmful.

15. The principle of "mediator":

a) To use an intermediate object, transporting or giving (sharing) action;

b) At the time of the object attached to another object, which can be easily removed.

16. Uniformity: objects that interact with the data must be made of the same material (or close to it on the properties).

17. Isolation and recycling parts: served its purpose and has become an unnecessary part of 
CURRENT RESEARCH JOURNAL OF PEDAGOGICS 2(8): 44-51, August

2021 DOI: https://doi.org/10.37547/pedagogics-crjp-02-08-11

ISSN 2767-3278

(C)2021 Master Journals

\section{Crossref do) 81 Google}

Accepted 26 th August, 2021 \& Published 31 th August, 2021

the object to be discarded (dissolved, evaporated, etc.) or modified during operation.

18. Change the state of aggregation of the object: it is not only simple transitions (for example, from solid to liquid), but transitions to intermediate states (for example, the usage of elastic solid things).

19. Discoloration:

a) To change the color of an object or environment;

b) Change the degree of transparency of an object or environment.

Evaluation of the solutions is based on compliance with the objective laws of development of systems.

The Usage of logic TIPS exercises

For the mathematical development of children, the following types of TIPS exercises are used.

"Finding common features": take two objects spaced away from each other on the sense axis, and find them as many common features as possible.

"Search analogs": name the object and find its analogues as many as possible that are similar to it on various essential features.

"The third is odd": take three objects, widely separated from each other in the sense axis; find in the first and second (or the first and third or second and third) sites are common features that are not available in the third (or second or first) "extra" object or the odd one.

The main function of the object "four" as a system - is quantity identification, the object "trapeze" - is the designation of a certain class of geometric shapes.

The essential features of the object "four" are as follows: consists of four units, and two smaller numbers ( 1 and 3 or 2 and 2); object "trapeze": two opposing sides are parallel, the other two - no. Minor signs or features of object "four": the letter $\mathrm{F}$ That is in the name of the word, etc.; object "trapeze": the name includes the letter m, similar to the roof of a house or a bus, and others.

Additional functions that can perform object "four" - is to decorate clothing, be part of a number, showing the shoe size, etc.; object "trapeze" - can be a part of the ornament on clothes, can be a coffee stand and others.

Subsystems for object "Four" - is four units, vowels and consonants, included in the word "four"; for object "trapeze" - is four sides, four tops, vowels and consonants included in the word "trapezoid".

Super system for the object "Four" - is a dozen, a hundred, mathematical abstraction; for object "trapeze" - is quads, mathematical abstractions.

So, common features are found in all highlighted in algorithm exercise "Finding common features" levels.

The using of logic TIPS exercises significantly improves the organization and focus of mental processing of children, giving them the skills of functional system analysis, which is effective in all kinds of activities 2 .

"What is included in". The teacher sets the 3 properties that are connected due to "super system - a system - a subsystem"; Children identify and substantiate this relationship or connection. Then extra objects are added, showing the relativity of the concepts of "super system", "system", "and sub - system".

"Yes - no". The teacher thinks of some "secret", children should guess it. To do this, they ask questions in such a form that the teacher can answer "yes" or "no" (also permitted to answer

2 Kumon Publishing. Subtraction. Grade $1 P D F$. Math Workbook, Kumon Publishing,USA, 2008, 96 pages. 
"yes", "no", "yes and no", "this is not important", "it is not Information").

For example, think of a number of the first five digits (4). Children ask: is it an even number? Any answer the second question would be: is the number more than two? If the number is odd and more than two, is given one last question: is it 3 ? "The Secret" is solved.

"Little People". Selected in advance the phenomenon or object seems to consist of many small men who can think, take actions, and behave differently. Men have different personalities and habits; they are subject to different commands. The game allows children to see and experience the natural phenomena, the nature of the interaction of objects, systems and their components, especially if the place of men, they put themselves.

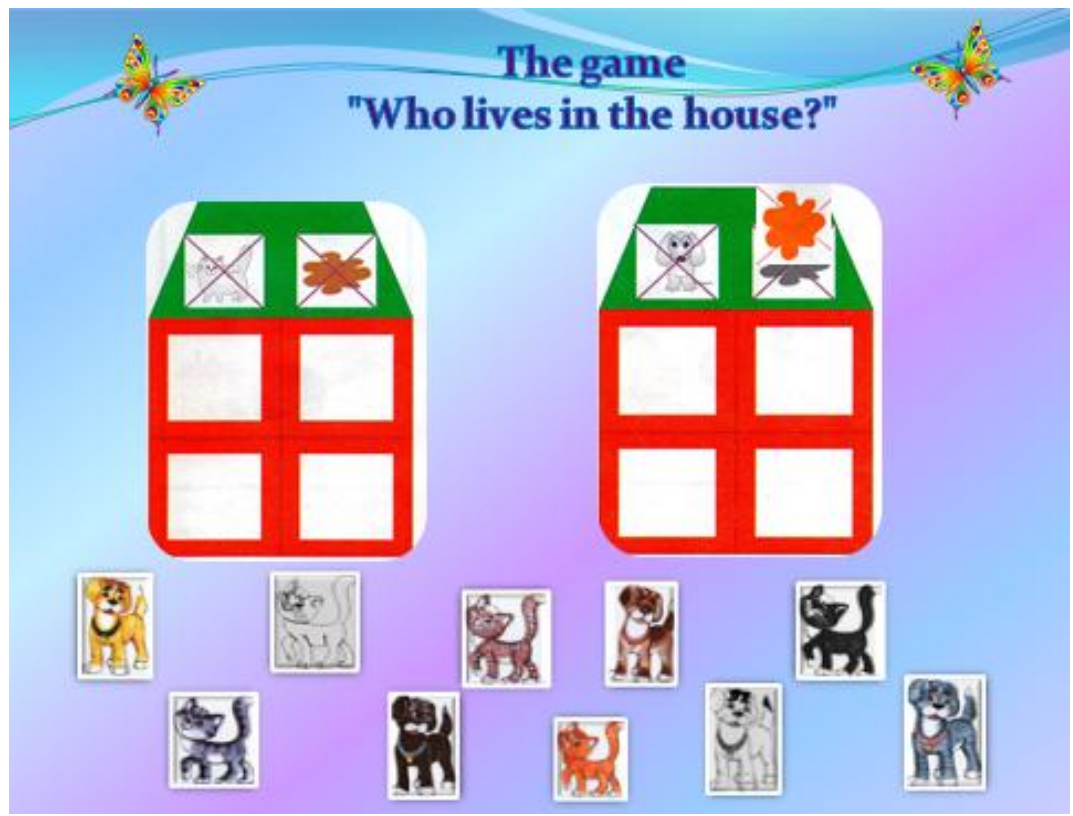

Organization reflection of children's activity

Reflection requires from all subjects of child's mathematical development process the choice of standardized criteria list. One of the possible lists can be considered the levels of creativity, first characterized in TIPS:

- changes in the parts of the system;

- one part of the system;

- the entire system;

- creation of a new system;
- construction of the principle of the creation of new systems.

With the help of this list of criteria the teacher and children can easily identify the qualitative characteristics of activities in the following spectrum:

- reproductive;

- compilation;

- procedural;

- comprehensive; 
CURRENT RESEARCH JOURNAL OF PEDAGOGICS 2(8): 44-51, August

2021 DOI: https://doi.org/10.37547/pedagogics-crjp-02-08-11

ISSN 2767-3278

(C)2021 Master Journals

Crossref do: 81 Google

Accepted $26^{\text {th }}$ August, 2021 \& Published 31 th August, 2021

- variation;

- constructive;

- innovative.

So, we have considered the possibilities of TIPS trends in the mathematical development and they are accessible and interesting for preschoolers. Staying uniform in shape, exercise, games, algorithms of TIPS are filled with content of varying degrees of difficulty depending on the characteristics of children and opportunities for teachers.

Use elements of TIPS can be considered in a various playful way:

-as an intellectual workout;

-check on the assimilation of mathematical concepts and terminology;

-to work with the basic concepts and topics of elementary mathematics;

-to improve the mental processes providing child's successful mathematical development.

In the first stage TIPS elements take the form of games without strict adherence to the rules of their implementation; the second - depending on the "mental age" of a child the basic concepts of systems analysis and logical operations of thought are introduced; the third - in the performance of tasks of varying difficulty emphasis is on the process of obtaining and evaluating results.

\section{REFERENCES}

1. Aromshtam O., Baranova O. Spatial geometry for kids. Developing activities. M .: Enas, 2005 .-- 94 p.

2. Arkhipova I.A. Preparing a child for school $\therefore$ Book for the parents of a future first grader. - Yekaterinburg: U - Factory, 2004 -- 215 p.

3. Beloshistaya A.V. Formation and development of mathematical abilities of preschoolers. A course of lectures for students of preschool faculties of higher educational institutions. - M .: VLADOS, 2003 -- 400p.

4. Dzhanpeisova G.E. To the problem of development in preschoolers of some ideas about the basic elements of geometric shapes. // J. Talim wa tarbia. - 2001. No. 3 6. - P.76 - 79 .

5. Kumon Publishing. Subtraction. Grade 1 PDF. Math Workbook, Kumon Publishing,USA, 2008, - 96 pages.

6. MUKHIDDINOV, M., SULAYMONOV, I., KHASANOVA, M., ASLANOVA, K., \& SHOMURODOVA, S. (2021). Ode genre and ideological-artistic features of erkin vahidov's odes. Journal of Contemporary Issues in Business and Government, 27(3), 1317-1323.

7. Filimonova, T. V. (2018). Substantiation of pedagogical conditions for preparing future educators for patriotic upbringing of children of senior preschool age. Збірник наукових праць [Херсонського державного університету]. Педагогічні науки, (82 (3)), 199-203.

8. Муслихиддин, М. К. (2021). THE VIRTUE OF THE WORD. ALISHER NAVOIY XALQARO JURNALI, 1(1).

9. Davletbaeva, D. N., Iakovleva, E. L., Kajumova, D. F., Karimova, A. A., Sadykova, A. G., Shvetsova, E. V., ... \& Yarhamova, D. Z. (2016). The model of formation of patriotism at schoolchildren by means of folk pedagogics. International Review of Management and Marketing, 6(2S). 
CURRENT RESEARCH JOURNAL OF PEDAGOGICS 2(8): 44-51, August

2021 DOI: https://doi.org/10.37547/pedagogics-crjp-02-08-11

ISSN 2767-3278

(C)2021 Master Journals

Crossref dof 81 Google

Accepted 26 $6^{\text {th }}$ August, 2021 \& Published 31 ${ }^{\text {th }}$ August, 2021

10. Nazmiya, M. (2019). IDEALOGICALARTISTIC CONCERN IN THE CREATION OF KHUSROW DEHLAVI AND ALISHER NAVOI. Глобус, (9 (42)).

11. Sahuichenko, V., Shynkarenko, V., Bezena, I., Perederii, O., \& Martynenko, O. (2020). State policy on the formation of students' civic and social competences in conditions of educational reform. Revista Educação \& Formação, 5(3), e3080.

12. Muhitdinova, N. M. (2021). Interpretation of mystical themes in Mirhasan Sadoi and muhammad ghazi's collection of poems. Asian Journal of Multidimensional Research (AJMR), 10(3), 538-548.

13. Muhiddinov, M. (2005). The perfect man is the ideal of literature. Tashkent: Yangi asr avlodi, 206.

14. http://www.kindereducation. com

15. http://www. virastayka.ru. 